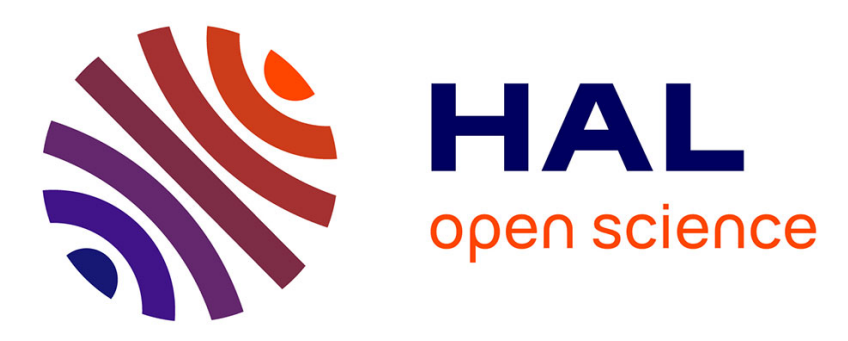

\title{
In vivo metabolism of diallyl disulphide in the rat: identification of two new metabolites
}

Emmanuelle Germain, Jacques Auger, Christian Ginies, Marie Hélène Siess, Caroline C. Teyssier

\section{- To cite this version:}

Emmanuelle Germain, Jacques Auger, Christian Ginies, Marie Hélène Siess, Caroline C. Teyssier. In vivo metabolism of diallyl disulphide in the rat: identification of two new metabolites. Xenobiotica, 2002, 32 (12), pp.1127-1138. 10.1080/0049825021000017902 . hal-02682483

\section{HAL Id: hal-02682483 \\ https://hal.inrae.fr/hal-02682483}

Submitted on 1 Jun 2020

HAL is a multi-disciplinary open access archive for the deposit and dissemination of scientific research documents, whether they are published or not. The documents may come from teaching and research institutions in France or abroad, or from public or private research centers.
L'archive ouverte pluridisciplinaire HAL, est destinée au dépôt et à la diffusion de documents scientifiques de niveau recherche, publiés ou non, émanant des établissements d'enseignement et de recherche français ou étrangers, des laboratoires publics ou privés. 


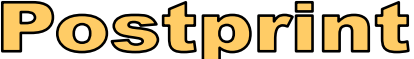

Version définitive du manuscrit publié dans / Final version of the manuscript published in :

Xenobiotica. 2002, 32 (12) : 1127-1138

\section{Author's bionote}

MH Siess is a senior scientist in the Unit of Food Toxicology which belongs to INRA

(France). She supervises a group studying the role of phytochemicals originating from fruits and vegetables on the prevention of cancer. She has studied, for 10 years, the chemopreventive effects of Allium species and published in 2001 a review on the chemoprevention of cancer by Allium. 
In vivo metabolism of diallyl disulphide in the rat: Identification of two new metabolites.

E. GERMAIN ${ }^{¥}$, J. AUGER ${ }^{\square}$ C. GINIES ${ }^{\#}$, M-H. SIESS ${ }^{\sharp} *$ and C. TEYSSIER ${ }^{¥ *}$

${ }^{\text {q}}$ Unité Mixte de Recherche de Toxicologie Alimentaire, Institut National de Recherche Agronomique - Université de Bourgogne, BP 86510, 17 rue Sully, 21065 Dijon Cedex, France.

Institut de Recherche sur la Biologie des Insectes, Centre National de Recherche Scientifique, Université F. Rabelais, Parc Grandmont, 37200 Tours, France.

\# Unité Mixte de Recherche des Arômes, Institut National de Recherche Agronomique Université de Bourgogne, BP 86510, 17 rue Sully, 21065 Dijon Cedex, France.

* Present address : Unité Amélioration, génétique et physiologie forestières, Institut National de Recherche Agronomique, Avenue de la Pomme de Pin - Ardon, BP 20619, 45166 Olivet cedex, France.

* Author for correspondence: M-H. SIESS; phone : 333806932 21; fax : 333806932 25; email: siess@dijon.inra.fr.

\section{Running title}

In vivo biotranformation of DADS in rat

Key words

DADS, metabolism, S-oxidation, pharmacokinetics, garlic, in vivo 


\section{ABSTRACT}

1. Diallyl disulphide (DADS), a compound that is formed from the organosulphur compounds present in garlic, is known for its anticarcinogenic effects in animal models.

2. The aim of the study was to identify and analyse the metabolites produced in vivo after a single oral administration of $200 \mathrm{mg} / \mathrm{kg}$ of DADS to rats. The organic sulphur metabolites present in the stomach, liver, plasma and urine were measured by gas chromatography coupled with mass spectrometry over a 15-day period.

3. Data indicate that DADS is absorbed and transformed into allyl mercaptan, allyl methyl sulphide, allyl methyl sulphoxide (AMSO) and allyl methyl sulphone $\left(\mathrm{AMSO}_{2}\right)$ which are detected throughout the excretion period. Overall, the highest amounts of metabolites are measured 48-72 hours after the DADS administration. $\mathrm{AMSO}_{2}$ is the most abundant and the most persistent of these compounds. The levels of all the sulphur compounds rapidly decline within the first week after administration and disappear during the second one. Only AMSO and $\mathrm{AMSO}_{2}$ are significantly excreted in urine.

4. These potential metabolites are thought to be active in the target tissues. Our data warrant further studies to check this hypothesis.

\section{Introduction}

Since early times, many beneficial properties have been ascribed to garlic for human health. Recent investigations have provided a scientific basis to these properties and have shown that garlic can interfere with different processes involved in the development of cardiovascular, neoplasic and several other diseases (Reuter 1995, Amagase et al. 2001). The reported 
biological effects have been attributed to the organosulphur compounds present in the bulb or formed after cutting or chopping the bulb.

Among these compounds, diallyl disulphide (DADS, figure 1), which accounts for $40 \%$ to 60 $\%$ of the essential oil of garlic, has often been reported to inhibit or reduce chemically induced carcinogenesis in rodents (Le Bon and Siess 2000, Milner 2001). DADS exerts a broad spectrum of effects on several stages involved in the process of carcinogenesis, including modulatory effects on drug metabolising enzymes (Yang et al. 2001), prevention of genotoxicity (Guyonnet et al. 2001), inhibition of cell proliferation, apoptosis and cell differentiation (Sundaram and Milner 1996, Lea and Ayyala 1997) and an immunostimulating effect (Kuttan 2000). In addition, DADS has also been shown to interact with cholesterol synthesis (Gebhardt and Beck 1996).

Although there is considerable knowledge about the anticarcinogenic effects of DADS, only one study has been dedicated to its in vivo metabolism and its distribution in rodents. Pushpendran et al. (1980) studied the uptake and the metabolic fate in mice of labelled DADS given at a sub-lethal dosage. The latter authors reported that DADS is rapidly absorbed, with a maximal concentration in the liver 90 minutes after ip. administration. $8 \%$ of the radioactivity present in the liver was identified as DADS. In addition, several ex vivo and in vitro systems have been used to analyse and identify the metabolites of DADS. In a study using an isolated perfused rat liver, DADS appeared to be converted to allylmercaptan (AM, figure 1) (Egen-Schwind et al. 1992a). In primary rat hepatocytes, the metabolites of DADS have been analysed (Sheen et al. 1999) and within 120 min the majority of DADS bulk disappeared from the extracellular fluid and was converted to AM and allyl methyl sulphide (AMS, figure 1). The amount of AM was greater than the amount of AMS. Lawson and Wang (1993) reported that DADS is converted to AM in presence of blood before reaching the liver or other organs. All these results suggest that the metabolism of DADS occurred by way of 
reduction and methylation. Furthermore, under other experimental conditions, the oxidation of DADS has been reported (Teyssier et al., 1999). Previous experiments in our laboratory have demonstrated the oxidation of DADS into allicin in the presence of human liver microsomes (Teyssier et al. 1999). Other naturally occurring organosulphur compounds such as diallyl sulphide (Brady et al. 1991) and dipropyl disulphide (Teyssier and Siess 2000) have also been shown to be oxidised. Similarly, Mitchell (1988) pointed out the importance of the S-oxidation of sulphides by monooxygenases as a pathway in the biotransformation of several sulphur-containing compounds.

The aim of this current study was to investigate the in vivo fate of DADS and its metabolites in rats after a single oral administration. For this purpose, we analysed xenobiotic distribution in various tissues, and determined their pharmacokinetic parameters. Special attention was paid to the hypothetical formation of S-oxidised metabolites. The study was performed in rats with one oral administration of $200 \mathrm{mg} / \mathrm{kg}$ of DADS. At distinct time intervals during 15 days, the concentrations of organosulphur compounds were determined in the stomach, plasma, liver and urine by gas chromatography coupled with mass spectrometry (GC-MS). The data confirmed the presence of AM and AMS as in vivo metabolites of DADS. Two new metabolites were detected and identified as allyl methyl sulphoxide (AMSO, figure 1) and allyl methyl sulphone $\left(\mathrm{AMSO}_{2}\right.$, figure1) by different analytical approaches.

[Insert figure 1 about here]

\section{Materials and methods}

\section{Chemicals}

AM, AMS, sodium metaperiodate, $p$-cymene, nonane and DADS were purchased from Sigma Aldrich Chemical (Strasbourg, France). DADS was purified by distillation under reduced 
pressure (95 \% purity checked by GC-MS) whereas AM (80 \% purity) and AMS (98 \% purity) were used as standards without further purification. Allicin (78\% purity) was synthesised by the action of metachloroperbenzoic acid on DADS as previously described (Mondy et al. 2001). All other reagents and organic solvents were of HLPC or analytical grades (SDS, Peypin, France). Dichloromethane was distilled prior to use for the solvent extractions.

\section{Synthesis of AMSO and $\mathrm{AMSO}_{2}$}

AMSO and $\mathrm{AMSO}_{2}$ were obtained by oxidation of AMS with sodium metaperiodate in a methanolic solution thawed on ice overnight (Furniss et al. 1989). The compounds were extracted before injection into gas chromatography-mass spectrometry (GC-MS) and gas chromatography-Fourier transformed infrared (GC-FTIR) in order to assess their structure. The reaction was total but gave a mixture of AMSO (85 \%) and $\mathrm{AMSO}_{2}(15 \%)$ as estimated by GC-MS.

\section{Animals and drug administration}

Male 8-week old Wistar rats ( $\mathrm{n}=55$, average weight 350 g) were purchased from Janvier (Le

Genest Saint Isle, France). Rats were housed in individual stainless-wire cages, maintained at $22^{\circ} \mathrm{C}$ with a $12 \mathrm{~h}$ light $/ 12 \mathrm{~h}$ dark cycle. They were fed ad libitum with standard diet (reference 20118S from HARLAN France (Gannat, France)) and water. The animals were fasted for 18 hours before and 6 hours after drug administration. DADS, dissolved in corn oil, was orally administrated at a dose of $200 \mathrm{mg}$ per $\mathrm{kg}$ body weight. Negative controls were included for 7 animals in order to check that no sulphur compounds were detectable in their tissues. After oral administration, animals were maintained separately in metabolic cages. Urine (kept under 
cold conditions) was collected every $24 \mathrm{~h}$ and stored at $-20^{\circ} \mathrm{C}$ until further analysis. Animals were killed by exsanguination under anaesthesia (isoflurane, $2.5 \%$ in oxygen) 10 ( $n=3), 20$ $(n=3), 40 \min (n=3), 1(n=3), 2(n=3), 6(n=3), 24(n=3), 48(n=4)$ and $72 h(n=3)$ after oral dosing and then every two days $(n=3)$ during the 12 remaining days of the experiment. Livers and stomachs were removed, weighed and stored at $-20^{\circ} \mathrm{C}$ until further analysis. Blood and urine were immediately centrifuged and were also stored at $-20^{\circ} \mathrm{C}$ prior to analysis.

\section{Sample preparation}

Sample preparation was performed as previously described (Teyssier and Siess 2000). Briefly, stomachs and livers were homogenised with a high-speed blendor in distilled water. $100 \mu \mathrm{l}$ of an ethanol solution containing $p$-cymene $\left(0.17 \mathrm{mg} \cdot \mathrm{ml}^{-1}\right)$, used as an internal standard (Martin-Lagos et al. 1995), was added to the homogenate. After adding $10 \% \mathrm{w} / \mathrm{v}$ trichloroacetic acid $30 \%$, the homogenate was centrifuged and the supernatant extracted three times with dichloromethane. The same protocol without homogenisation was used for the plasma samples whereas urine samples were subjected to only the dichloromethane extraction. The extracts were then concentrated by evaporation under a nitrogen stream to a final volume of $500 \mu \mathrm{l}$. To this volume, $100 \mu \mathrm{l}$ of nonane dissolved in dichloromethane $(0.15$ mg.ml ${ }^{-1}$ ) was added in order to standardise each sample concentration and an aliquot of $2 \mu \mathrm{l}$ was then injected into the chromatograph under the conditions described below.

\section{GC-MS conditions for DADS, AM, AMS, AMSO and $\mathrm{AMSO}_{2}$ analysis}

GC-MS was carried out using a Agilent Technologies 6890 gas chromatograph coupled to Agilent Technologies 5973 Mass Selective Detector using a capillary DB ${ }^{\mathrm{TM}} 1701$ column (30 m x 0.32 mm I.D., $1 \mu \mathrm{m}$ film thickness), a splitless injection and an electronic ionisation at $70 \mathrm{eV}$. The oven was programmed from $35^{\circ} \mathrm{C}(2 \mathrm{~min})$ to $220^{\circ} \mathrm{C}$ at a rate of $5^{\circ} \mathrm{C} \cdot \mathrm{min}^{-1}$. The 
other conditions were as follows: carrier gas, helium (constant velocity fixed at $35 \mathrm{~cm} / \mathrm{sec}$ ); temperature of the injection port, $200^{\circ} \mathrm{C}$. Peak identifications were based on comparison with retention times and spectra of standards. Each sample was analysed twice. For the first acquisition, GC-MS was used in scan mode from m/z 28 to $300 \mathrm{amu}$ in order to ascertain the identification of compounds by comparison with standards. For the second acquisition, GCMS was used in Selected Ion Monitoring (SIM) mode. The quantification of AM, AMS, AMSO, $\mathrm{AMSO}_{2}$ and DADS was achieved by monitoring the ions at m/z 74, 88, 104, 120 and 146 respectively. The purity was continuously checked by the control of the ratio between this quantifying ion and another one, specific for each compound. Chemical ionisation was performed with $\mathrm{NH}_{3}$ as gas reactant.

\section{GC-MS conditions for allicin analysis}

For allicin analysis, we applied the recently developed specific GC-MS method (Mondy et al. 2001). Briefly, analyses were carried out on a benchtop Perkin Elmer turbomass system with a split-splitless injector and a fused-silica capillary column (10 m x $0.32 \mathrm{~mm})$ with 4- $\mu \mathrm{m}$ methylsilicon coating. The carrier gas was helium and the oven temperature program was $5^{\circ} \mathrm{C} \cdot \mathrm{min}^{-1}$ from 70 to $250^{\circ} \mathrm{C}$. The injection port temperature was $200^{\circ} \mathrm{C}$. Total ion chromatograms and mass spectra were recorded in the electron impact ionisation mode of 70

$\mathrm{eV}$. The transfer line and the source temperature were maintained at $150^{\circ} \mathrm{C}$. Peak identifications were based on comparison with retention times and spectra obtained with pure allicin. These GC-MS conditions allowed the direct detection of allicin directly and the detection of 3-vinyl[4]-1,2 dithiin and 2-vinyl[4]-1,3 dithiin, two compounds formed from the allicin degradation during GC-process (Mondy et al. 2001). The limit of detection of allicin was estimated with a standard solution at $15 \mathrm{ng}$. 
GC-FTIR conditions for AMSO and $\mathrm{AMSO}_{2}$ analysis

AMSO and $\mathrm{AMSO}_{2}$ from dichloromethane extract were identified by GC-FTIR analysis using a Biorad Digilab FTS 60A spectrometer. This equipment was connected by means of a digilab Tracer ${ }^{\circledR}$ direct-deposition interface to a Hewlett-Packard HP 5890 serie II (Palo Alto, CA) gas chromatograph, which was equipped with a splitless-split injector. GC separation was similar to the above mentioned method (GC-MS conditions for DADS, AM, AMS, AMSO and $\mathrm{AMSO}_{2}$ analysis).

\section{Quantitative determination of the organosulphur compounds}

For each sulphur compound, the sensitivity and linearity of the GC-MS detector used in the SIM mode was calculated from a series of standard solutions dissolved in dichloromethane. The response coefficient (a) was calculated from the curve $\mathrm{Y}=\mathrm{a} \mathrm{X}+\mathrm{b}$ where $\mathrm{Y}$ is the adjusted area (with the areas of $p$-cymene and nonane) of the quantified ion and $\mathrm{X}$ is the quantity of the compound (ng). The response coefficient of all other compounds was essentially similar, between 1.24 and 4.19, except for $\mathrm{AMSO}_{2}$ which was low (0.32). The lowest correlation coefficient $\left(\mathrm{r}^{2}\right)$ was about 0.995 . The limits of detection varied depending on the sulphur compounds and were $0.04 \mathrm{ng}$ for DADS, $0.64 \mathrm{ng}$ for AM, $0.04 \mathrm{ng}$ for AMS, $0.03 \mathrm{ng}$ for $\mathrm{AMSO}$ and $0.11 \mathrm{ng}$ for $\mathrm{AMSO}_{2}$.

The concentration of each sulphur compound in the biological samples was calculated by the ratio between the area of the sulphur compound and the product of $p$-cymene area and nonane area. After excluding every value beneath the linearity region of the detector, the amount of each compound was obtained by integrating its specific response coefficient. Results were given as a mean of three separate experiments, in $\mu \mathrm{g}^{-g^{-1}}$ of organ.

\section{Pharmacokinetic analysis}


The non-compartimental method was used to calculate the pharmacokinetic parameters with the Kinetica ${ }^{\circledR}$ software (InnaPhase, Champs sur Marne, France). The area under the plasma concentration-time curve (AUC) was computed using the trapezoidal Log Linear Method, when $\mathrm{Cn}>\mathrm{Cn}-1$. The elimination half-life $\left(t_{1 / 2}\right)$ was calculated as $t_{1 / 2}=\ln 2 \cdot \mathrm{L}_{\mathrm{z}}{ }^{-1}$ where $\mathrm{L}_{\mathrm{z}}$ is the elimination rate constant. The plasma clearance $\left(C l_{\mathrm{p}}\right)$ was calculated as $C l_{\mathrm{p}}=\mathrm{dose}$.AUC ${ }^{-1} . T_{\max }$ corresponded to the time for which the concentration was maximum $\left(C_{\max }\right)$.

\section{Results}

[Insert figure 2 about here]

[Insert figure 3 about here]

\section{Identification of volatile metabolites}

After DADS administration to rats, the parent molecule was detected in almost all analysed tissues within the first hours (data not shown). In addition, the DADS metabolites such as AM, AMS and two unknown compounds were detected in all the tested organs. Despite the specificity of the method used, neither allicin nor vinyl dithiines were detected. Figure 2 shows a gas chromatogram of the volatile components detected in the stomach. DADS, AM and AMS were identified by comparing their retention times and mass spectra with those of standard compounds. The molecular weights of the two unknown compounds, 104 and 120, were determined by chemical ionisation in GC-MS. Due to the absence of the corresponding standards, their identification was achieved by different approaches summarised in table 1. Based on GC-MS data (figure 3), the intensity of the ion at the $\mathrm{m} / \mathrm{z}$ ratio of $(\mathrm{M}+2)$ indicated the presence of one sulphur atom in each compound. The observed isotopic ratios were in agreement with the calculated ratios for molecules containing one atom of sulphur, four atoms of carbon, eight atoms of hydrogen and one or two atoms of oxygen for the first and the second metabolites respectively. Since oxidation of sulphur compounds has been reported in 
the literature (Williams et al. 1966, Brady et al. 1991, Nickson et al. 1995, Teyssier and Siess 2000), we hypothesised that these two unknown metabolites corresponded to AMSO and $\mathrm{AMSO}_{2}$. Subsequently, the chemical synthesis of these compounds was undertaken. Their chemical structures were ascertained by GC-MS and GC-FTIR. Indeed, the infrared spectra showed strong absorption bands for the sulphoxide moiety $\left(v_{S=O}=998 \mathrm{~cm}^{-1}\right)$, for the sulphone moiety (symmetric stretching $v_{\mathrm{SO} 2}=1136 \mathrm{~cm}^{-1}$; asymmetric stretching $v_{\mathrm{SO} 2}=1289 \mathrm{~cm}^{-1}$ ) and small absorption bands for the allyl chain $\left(v_{\mathrm{C}=\mathrm{C}}=1641 \mathrm{~cm}^{-1} ; v_{=\mathrm{C}-\mathrm{H}}=3088 \mathrm{~cm}^{-1}\right)$ (Socrates 1994). Hence, the in vivo metabolites were then compared to the synthesised standards and were identified as $\mathrm{AMSO}$ and $\mathrm{AMSO}_{2}$.

\section{[Insert table 1 about here]}

\section{Metabolite profiles in stomach, liver, plasma and urine}

\section{[Insert figure 4 about here]}

Figure 4 shows the time-dependent tissue concentrations of DADS and its metabolites, AM, AMS AMSO and $\mathrm{AMSO}_{2}$ after DADS oral administration. In the stomach, all these compounds were detected with various rates of appearance and different concentration-time profiles (figure 4A). The highest levels of DADS were found during the 24 hours. Thereafter, it sharply decreased and was not detectable 3 days after oral administration. In contrast, $\mathrm{AMSO}_{2}$ reached a maximal concentration later in the period of follow-up, i.e. on the $3^{\text {rd }}$ day, and was still detectable for 11 days (figure 4A). In the plasma and the liver, $\mathrm{AMSO}_{2}$ was found to be the most abundant and persistent compound. The other compounds were, by rank order, AMSO and then AMS. In plasma, AM was barely detectable and DADS appeared transiently at 20 minutes after administration (data not shown). $\mathrm{AMSO}_{2}$ concentration reached its maximum on the $2^{\text {nd }}$ day and thereafter decreased, formed a plateau between day 3 and day 5 and became undetectable at day 9 (figure 4C). In liver, DADS and AM were detected only 
during the first hours (data not shown). The levels of $\mathrm{AMSO}_{2}$ increased extensively over the first two days (figure 4C). After reaching a maximum, the level of $\mathrm{AMSO}_{2}$ slowly decreased but was still detected 11 days after DADS administration. In urine, neither AM nor DADS were detected (figure 4D). Only trace amounts of AMS were excreted only on the $2^{\text {nd }}$ day, whereas $\mathrm{AMSO}$ and $\mathrm{AMSO}_{2}$ were excreted throughout a longer period. The $\mathrm{AMSO}_{2}$ concentration-time profile was similar to the one observed in plasma with its highest level in urine corresponding to $15 \%$ of the maximal plasma level (figure 4C-4D).

\section{Pharmacokinetic parameters}

The plasma concentration-time curve of the metabolites of DADS after oral administration to the rat is shown in figure 5 and the pharmacokinetic parameters are summarised in table 2. In the case of DADS, only the $C_{\max }$ and $T_{\max }$ were determined since the plasma concentrations were too low to enable an accurate determination of other pharmacokinetic parameters. $C_{\max }$ of the metabolites were higher than that of DADS $\left(0.001 \mathrm{mmol}^{-1} \mathrm{l}^{-1}\right.$ as were plasma $T_{\max }$. Indeed, the DADS $T_{\max }$ was estimated to be less than $1 \mathrm{~h}$ whereas this time increased to $24 \mathrm{~h}$ for AM and AMS and to $48 \mathrm{~h}$ for AMSO and $\mathrm{AMSO}_{2}$. The AUC for AM of 0.324 h.mmol.l ${ }^{-1}$ increased for the other metabolites until the maximal value of 116.86 h.mmol. l $^{-1}$ determined for $\mathrm{AMSO}_{2}$.

[Insert table 2 about here]

[Insert figure 5 about here]

\section{Discussion}

The present study was carried out in order to investigate the in vivo biotransformation of DADS after oral administration to rats. For this purpose, we applied a quantitative and sensitive GC-MS method suitable for organosulphur compound analysis, which has already 
been validated (Martin-Lagos et al. 1995). We measured not only the amounts of DADS but also those of AM, AMS, AMSO and $\mathrm{AMSO}_{2}$ which were identified as DADS metabolites in the stomach, plasma, liver and urine. Based upon their plasma concentrations, their pharmacokinetic parameters were determined. We observed large interindividual variations which are particularly representative in the bioavailability (coefficient of variation of DADS : not determined, $\mathrm{AM}$ : $81 \%$, AMS : $32 \%$, AMSO : $\left.38 \%, \mathrm{AMSO}_{2}: 7 \%\right)$. Our results, reported herein, show that DADS is absorbed, but due to its low plasma concentrations, it was not possible to accurately determine the related pharmacokinetic parameters. However, the uptake of DADS in the liver was observed only during the first 2 hours after dosing (data not shown), and DADS was transiently detected in plasma and totally undetectable in the urine. The DADS levels in the liver and plasma did not exceed $0.5 \%$ of the DADS level in the stomach. These data are in accordance with a previous study in humans in which no DADS was detected in the blood and urine after ingestion of raw garlic (Amagase et al. 2001). The fact that DADS was hardly detected in any sample could be linked with its metabolism. Indeed, in an experiment in our laboratory using an isolated rat liver perfused with DADS, the apparent $t_{1 / 2}$ of DADS was estimated to be less than to 1 hour (unpublished data). In spite of the impossibility to assess the in vivo pharmacokinetic parameters of DADS, all these observations, taken together, strongly suggest that once absorbed, DADS is rapidly and extensively metabolised.

Our data show that DADS is transformed into AM, AMS, AMSO and $\mathrm{AMSO}_{2}$. Among these metabolites, $\mathrm{AMSO}_{2}$ and AMSO are the major and more persistent volatile metabolites found in all assayed tissues. $\mathrm{AMSO}_{2}$ appears to be the final metabolite since no new metabolite was detected when $\mathrm{AMSO}_{2}$ level decreased. In the same way, Nickson et al. (1995) reported that only dipropyl sulphone was detected in the urine of rats after oral ingestion of dipropyl sulphoxide, indicating the absence of subsequent biotransformation of the sulphone. AM and 
AMS were actually detected but their bioavailabilities (table 2) were lower than those of the S-oxidised metabolites (table 2). The rapid elimination of AM and AMS in the breath described by Rosen and co-workers (2001) could explain their moderate amounts and low bioavailability observed in our study. However, an alternative hypothesis is that AMS is the precursor of AMSO and $\mathrm{AMSO}_{2}$. This hypothesis is consistent with the $T_{\max }$ of the metabolites which are compatible with sequential DADS transformation into AM to AMS to AMSO and finally to $\mathrm{AMSO}_{2}$ (table 2).

Interestingly, as far as pharmacokinetic profiles were concerned, AMSO and $\mathrm{AMSO}_{2}$ presented similar patterns. In the liver and in the plasma, they were characterised by an initial sharp rise during the first 2 days followed by a slow decline lasting 3 to 9 days suggesting a slow elimination. This phenomenon was unexpected since the overall hydrophilic nature of Soxidised metabolites would favour a rapid and complete urinary excretion. However, due to the charge separation of sulphur-oxygen linkages in the S-oxidised metabolites, it is possible that these metabolites may interact more strongly with proteins and lipids and thereby be retained in the body, delaying their overall excretion. Similar pharmacokinetic results have been described during a study in rats on the bioavailability of vinyldithiins, other transformation products of allicin (Egen-Schwind et al. 1992b). These latter compounds are additional transformation products of allicin with elimination half-lives of about $5 \mathrm{~h}$ and were detected in many tissues over a period of $24 \mathrm{~h}$, but the maximal serum concentration was observed within the 30 first min after ingestion. In any case, the poor elimination of the sulphone correlates with the persistence of these sulphur compounds in plasma enabling their availability to the organism.

In good agreement with the literature, our study confirms that the liver plays a major role in the in vivo fate of DADS not only in terms of metabolism but also as a storage site. Indeed, the liver it was found the organ with the highest concentrations of all sulphur compounds 
(figure 4) and this phenomenon is further highlighted when the organ weight is taken into account. Moreover, the close quantitative and qualitative profiles obtained in the liver, plasma and urine for sulphur compounds strongly suggest that their output from the liver is performed by the plasma, and subsequently to the urine. The well-known poor elimination of sulphone by the kidney before the passing on to urine is also observable in our study by the persistence of these sulphur compounds in plasma.

This study has clearly established the presence of volatile metabolites in several organs after DADS ingestion but the formation of other metabolites can not be ruled out. In particular, it has been reported that several glutathione conjugates are formed from diallyl sulphide (Jin and Baillie 1997) and dipropyl disulphide (Teyssier and Siess 2000), which could also happen during the DADS metabolic process. Hence, if those conjugates actually exist, it would be of major interest to compare their levels with those of $\mathrm{AMSO}$ and $\mathrm{AMSO}_{2}$.

In conclusion, we confirmed that AM and AMS are in vivo metabolites of DADS and we identified $\mathrm{AMSO}$ and $\mathrm{AMSO}_{2}$ as new and predominant metabolites of DADS in vivo in rats. Previously, DADS has been assumed to be one of the active components of garlic in vivo. Nevertheless, due to the rapid and extensive hepatic metabolism described herein, there seems to be no systemic bioavailability of DADS after oral administration. Taking into account the time of exposure and the quantity of the different metabolites of DADS, the oxidised compounds are involved in the beneficial effects ascribed to garlic. Further studies are needed to assess the biological effects of these metabolites of DADS.

\section{References}

Amagase, H., Petesch, B. L., Matsuura, H., Kasuga, S., and Itakura, Y., 2001, Intake of garlic and its bioactive components. Journal of Nutrition, 131, 955S-962S. 
Brady, J. F., Ishizaki, H., Fukuto, J. M., Lin, M. C., Fadel, A., Gapac, J. M., and Yang, C. S., 1991, Inhibition of cytochrome P-450 2E1 by diallyl sulfide and its metabolites. Chemical Research in Toxicology, 4, 642-647.

Egen-Schwind, C., Eckard, R., and Kemper, F. H., 1992a, Metabolism of garlic constituents in the isolated perfused rat liver. Planta Medica, 58, 301-305.

Egen-Schwind, C., Eckard, R., Jekat, F. W., and Winterhoff, H., 1992b, Pharmacokinetics of vinyldithiins, transformation products of allicin. Planta Medica, 58, 8-13.

Furniss, B.S., Hannaford, A.J., Smith, P.W.G., and Tatchell, A.R., 1989, VOGEL's text book of practical organic chemistry. fifth edition (Arlow UK: Willey, J. and son)

Gebhardt, R., and Beck, H., 1996, Differential inhibitory effects of garlic-derived organosulfur compounds on cholesterol biosynthesis in primary rat hepatocyte cultures. Lipids, 31, 1269-1276.

Guyonnet, D., Belloir, C., Suschetet, M., Siess, M. H., and Le Bon, A. M., 2001, Antimutagenic activity of organosulfur compounds from Allium is associated with phase II enzyme induction. Mutation Research, 495, 135-145.

Jin, L., and Baillie, T. A., 1997, Metabolism of the chemoprotective agent diallyl sulfide to glutathione conjugates in rats. Chemical Research in Toxicology, 10, 318-327.

Kuttan, G., 2000, Immunomodulatory effect of some naturally occuring sulphur-containing compounds. Journal of Ethnopharmacology, 72, 93-99.

Lawson, L. D., and Wang, Z. J., 1993, Pre-hepatic fate of the organosulfur compounds derived from garlic (Allium sativum). Planta Medica, 59, A688-A689 
Le Bon, A. M., and Siess, M. H., 2000, Organosulfur compounds from Allium and the chemoprevention of cancer. Drug Metabolism and Drug Interaction, 17, 51-79.

Lea, M. A., and Ayyala, U. S., 1997, Differentiating and growth inhibitory effects of diallyl disulfide on cancer cells. International Journal of Oncology, 11 , 181-185.

Martin-Lagos, R. A., Serrano, M. F., and lopez, M. D. R., 1995, Determination of organic sulphur compounds in garlic extracts by gas chromatography and mass spectrometry. Food Chemistry, 53, 91-93.

Milner, J. A., 2001, A historical perspective on garlic and cancer. Journal of Nutrition, 131, 1027S-1031S.

Mitchell, S. C., 1988, Biological consequences of drug sulphoxidation. Drug Metabolism and Disposition, 6, 245-252.

Mondy, N., Naudin, A., Christides, J. P., Mandon, N., and Auger, J., 2001, Comparison in GC-MS and HPLC in Allium volatiles analysis. Chromatographia, 53, S356-S360

Nickson, R. M., Mitchell, S. C., and Zhang, A. Q., 1995, Fate of dipropyl sulphone in rat. Xenobiotica, 25, 1391-1398.

Pushpendran, C. K., Devasagayam, T. P., Chintalwar, G. J., Banerji, A., and Eapen, J., 1980, The metabolic fate of [35S]-diallyl disulphide in mice. Experientia, 36, 1000-1001.

Reuter, H. D., 1995, Allium sativum and allium ursinum: part 2. Pharmacology and medicinal application. Phytomedicine, 2, 73-91.

Rosen, R. T., Hiserodt, R. D., Fukuda, E. K., Ruiz, R. J., Zhou, Z., Lech, J., Rosen, S. L., and Hartman, T. G., 2001, Determination of allicin, S-allylcysteine and volatile 
metabolites of garlic in breath, plasma or simulated gastric fluids. Journal of Nutrition, 131, 968S-971S.

Sheen, L. Y., Wu, C. C., Lii, C. K., and Tsai, S. J., 1999, Metabolites of diallyl disulfide and diallyl sulfide in primary rat hepatocytes. Food \& Chemical Toxicology, 37, 11391146.

Socrates, G., 1994, Infrared characteristic group frequencies. Tables and charts. second edition (Chichester, England: Wiley, J. and son)

Sundaram, S. G., and Milner, J. A., 1996, Diallyl disulfide induces apoptosis of human colon tumor cells. Carcinogenesis, 17, 669-673.

Teyssier, C., Guenot, L., Suschetet, M., and Siess, M. H., 1999, Metabolism of diallyl disulfide by human liver microsomal cytochromes P- 450 and flavin-containing monooxygenases. Drug Metabolism and Disposition, 27, 835-841.

Teyssier, C., and Siess, M. H., 2000, Metabolism of dipropyl disulfide by rat liver phase I and phase II enzymes and by isolated perfused rat liver. Drug Metabolism and Disposition, 28, 648-654.

Williams, K. I., Burstein, S. H., and Layne, D. S., 1966, Metabolism of dimethyl sulfide, dimethyl sulfoxide, and dimethyl sulfone in the rabbit. Archives of Biochemistry and Biophysics, 117, 84-87.

Yang, C. S., Chhabra, S. K., Hong, J. Y., and Smith, T. J., 2001, Mechanisms of inhibition of chemical toxicity and carcinogenesis by diallyl sulfide (DAS) and related compounds from garlic. [Review] [71 refs]. Journal of Nutrition, 131, 1041S-1045S. 


\section{Acknowledgements.}

We would like to thank Etienne Sémon and Joëlle Chevalier for his technical assistance.

This research is carried out with the framework of the EU Garlic \& Health project (QLK1-

CT-1999-00498). We acknowledge the financial support of the EU. 
Table 1. Chemical characteristics of the AMSO and $\mathrm{AMSO}_{2}$ metabolites .

\begin{tabular}{|c|c|c|c|c|c|}
\hline \multirow[b]{2}{*}{ AMSO } & \multirow{2}{*}{$\begin{array}{r}\text { MW } \\
104\end{array}$} & \multirow{2}{*}{$\begin{array}{c}\mathrm{Cl}^{\mathrm{a}} \\
(\mathrm{MH})^{+} \\
105\end{array}$} & \multicolumn{2}{|c|}{ isotopic ratio $(\%)^{b}$} & \multirow{2}{*}{$\begin{array}{l}\text { formula } \\
\mathrm{C}_{4} \mathrm{H}_{8} \mathrm{SO}\end{array}$} \\
\hline & & & $106 / 105$ & $5.95(5.36)$ & \\
\hline \multirow{3}{*}{$\mathrm{AMSO}_{2}$} & \multirow{3}{*}{120} & \multirow{3}{*}{121} & $107 / 105$ & $4.71(4.6)$ & \multirow{3}{*}{$\mathrm{C}_{4} \mathrm{H}_{8} \mathrm{SO}_{2}$} \\
\hline & & & $122 / 121$ & $5.80(5.40)$ & \\
\hline & & & $123 / 121$ & $4.72(4.8)$ & \\
\hline \multicolumn{6}{|c|}{${ }^{\mathrm{a}}$ : chemical ionisation. } \\
\hline
\end{tabular}


Table 2. Pharmacokinetic parameters of DADS and its metabolites after a single oral administration.

\begin{tabular}{|c|c|c|c|c|c|}
\hline & DADS & $\mathrm{AM}$ & AMS & AMSO & $\mathrm{AMSO}_{2}$ \\
\hline$t_{1 / 2}(\mathrm{~h})$ & n.d. ${ }^{a}$ & 4.39 & 6.78 & 7.16 & 8.64 \\
\hline $\mathrm{C}_{\max }\left(\mathrm{mmol.l} \mathrm{I}^{-}\right.$ & 0.001 & 0.008 & 0.008 & 0.376 & 1.44 \\
\hline \multicolumn{6}{|l|}{ 1) } \\
\hline $\mathbf{T}_{\max }(\boldsymbol{h})$ & $<1^{\mathrm{b}}$ & 24 & 24 & 48 & 48 \\
\hline AUC total & n.d. & 0.324 & 0.328 & 23.75 & 116.86 \\
\hline \multicolumn{6}{|l|}{ (h.mmol. I $^{-1}$ ) } \\
\hline $\mathrm{Cl}_{p}\left(\mathrm{l} . \mathrm{h}^{-1}\right)$ & n.d. & 1.475 & 1.455 & 0.020 & 0.004 \\
\hline
\end{tabular}

$\overline{\text { Parameters were calculated from three separate experiments. Data are means, }} \mathrm{n}=3$.

${ }^{\mathrm{a}}$ not determined. ${ }^{\mathrm{b}}$ estimated value. 


\section{Legends for figures.}

Figure 1. Structure of DADS and its metabolites .

Figure 2. Total Ionic Current chromatogram of extracted stomach ( $2^{\text {nd }}$ day) obtained on GCMS. Peaks : 1 : AM; 2 : AMS; 3 : nonane; $4:$ p cymene; 5 : DADS; $6:$ AMSO; $7: \mathrm{AMSO}_{2}$;

* : unidentified compounds detected both in extracts originating from control animals and DADS-treated animals.

Figure 3. Mass spectra of AMSO (A) and $\mathrm{AMSO}_{2}$ (B).

Figure 4. Concentrations of volatile metabolites in the stomach, liver, plasma and the urine after one oral administration of DADS to male rats $\left(200 \mathrm{mg} \cdot \mathrm{kg}^{-1}\right)$. Results are given as a mean of three separate experiments, expressed in $\mu \mathrm{g} . \mathrm{g}^{-1}$ of organ..

Figure 5. Plasma concentration-time curve of metabolites of DADS after one oral administration of DADS (200 mg.kg-1) to male rats. Values are the means of three separate experiments \pm SEM. After 75 hours for AM and AMS, and after 125 hours for AMSO, the measure amounts were beneath the detection limit. 


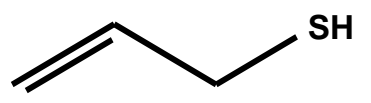

Allyl mercaptan, $A M$

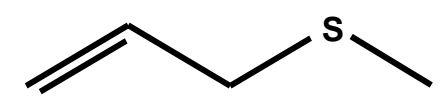

Allyl methyl sulphide, AMS

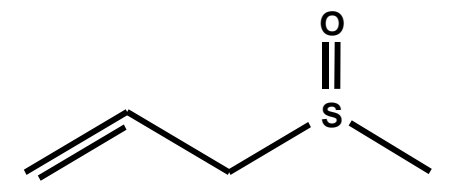

Allyl methyl sulphoxide, AMSO

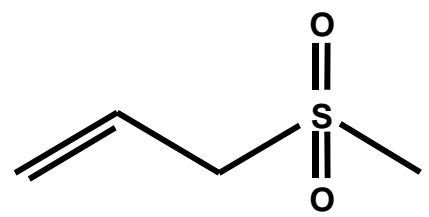

Allyl methyl sulphone, $\mathrm{AMSO}_{2}$<smiles>C=CCSSCC=C</smiles>

Diallyl disulphide, DADS<smiles>C=CCSS(=O)CC=C</smiles>

Allicin, diallyl thiosulphinate, DADSO 


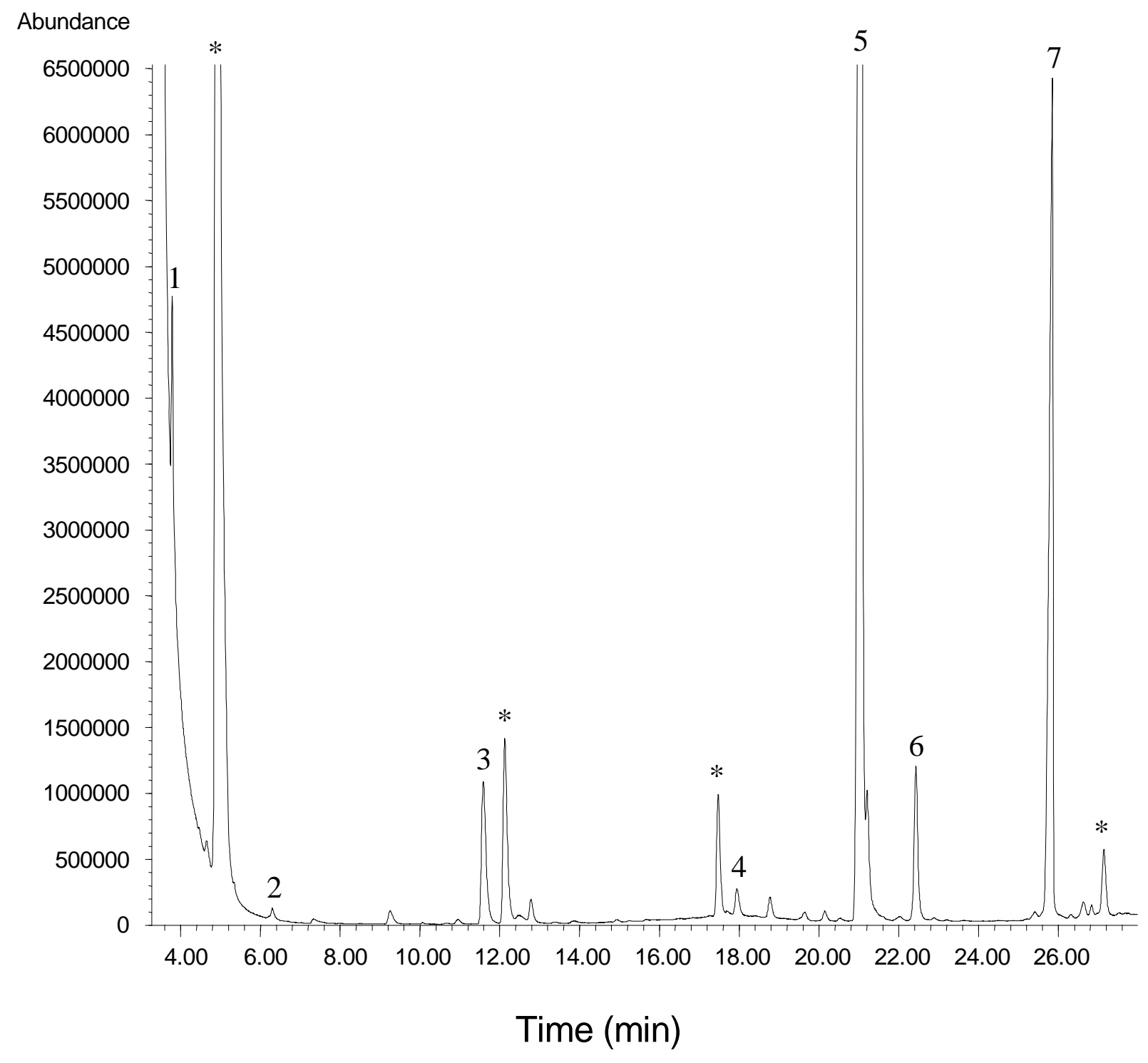




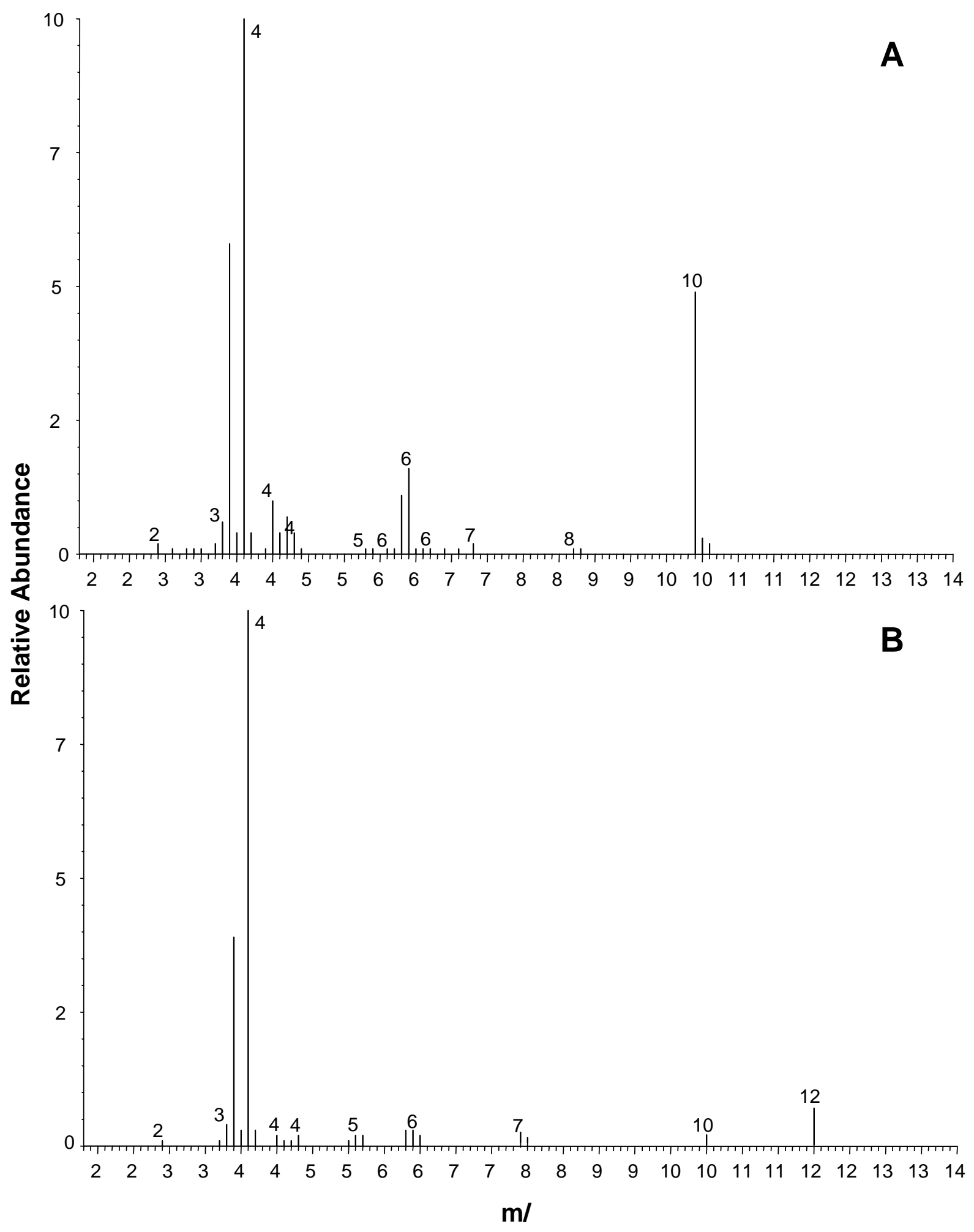



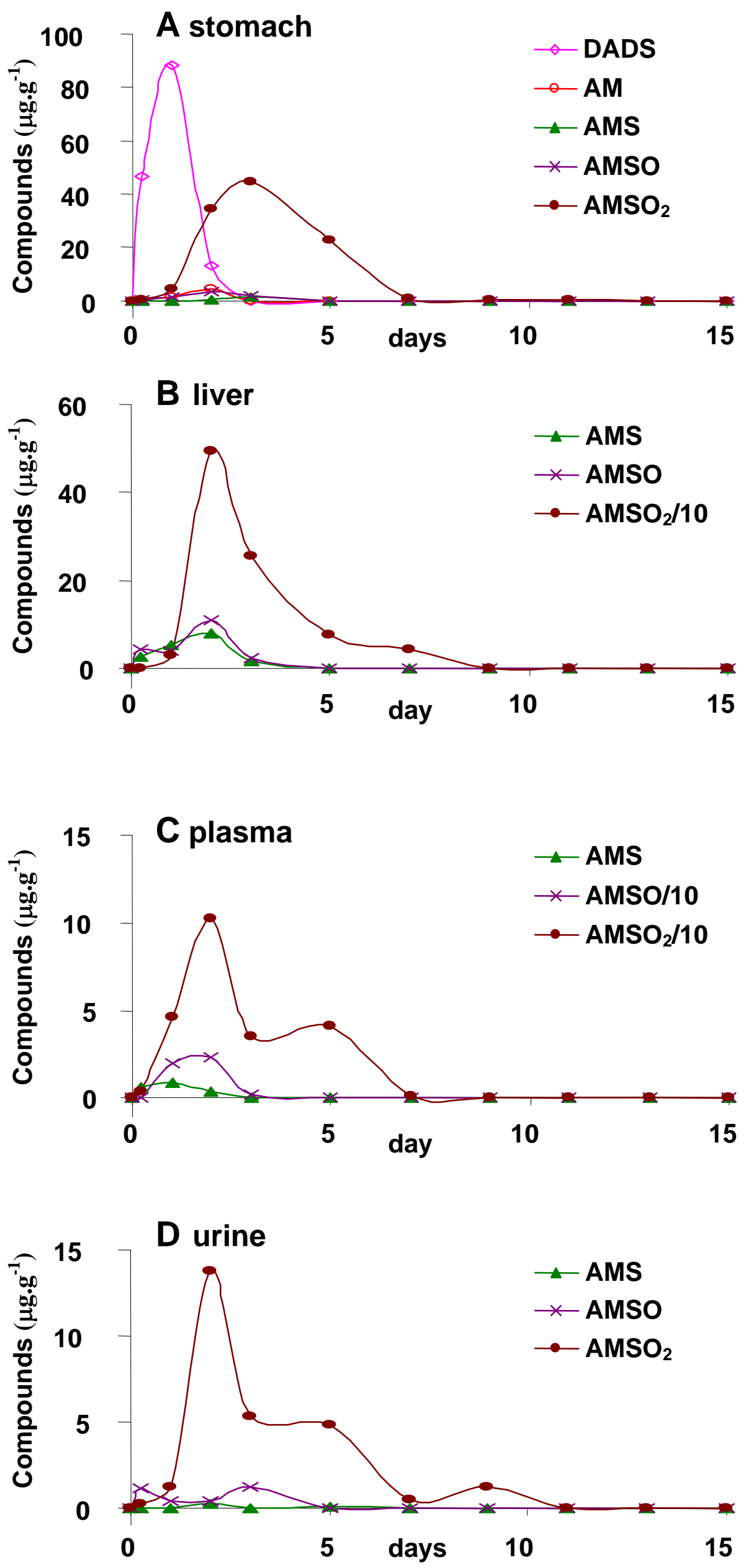


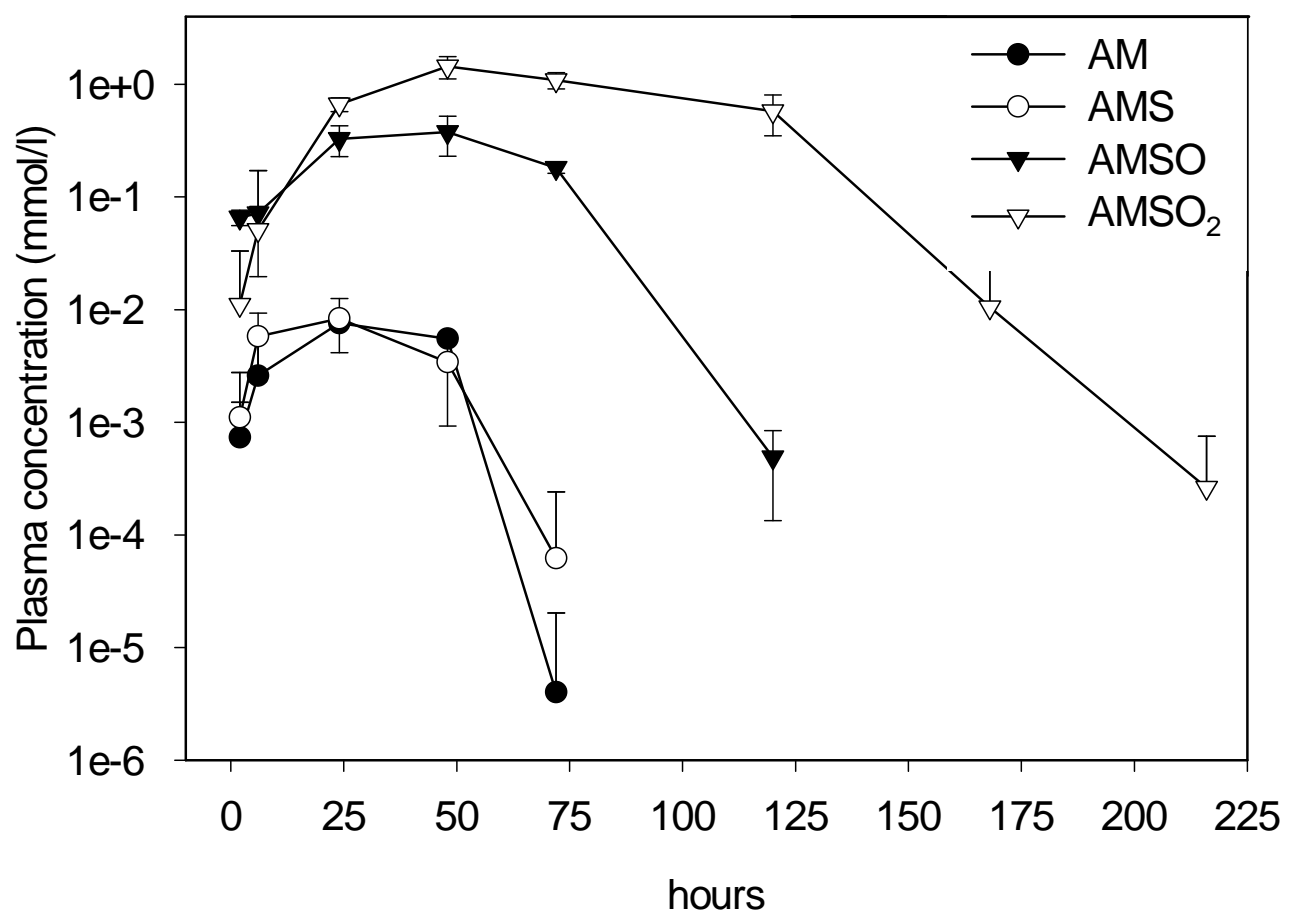

